\title{
A NONMODULAR COMPACT CONNECTED TOPOLOGICAL LATTICE ${ }^{1}$
}

DON E. EDMONDSON

The purpose of this note is to present an example of a nonmodular topological lattice which is compact and connected. The question of the existence of such a lattice was raised by Professor A. D. Wallace in a communication to me concerning his researches in topological lattices. The example will be a compact, connected portion of three space in its metric topology.

Let $L=\left\{(x, y, z) \in R^{3} \mid 0 \leqq x \leqq 1,0 \leqq y \leqq 1\right.$, and $\left.0 \leqq z \leqq x(1-y)\right\}$ and define the relation $\leqq$ on $L$ such that $\left(x_{1}, y_{1}, z_{1}\right) \leqq\left(x_{2}, y_{2}, z_{2}\right)$ if and only if (1) $x_{1} \leqq x_{2}$, (2) $y_{1} \leqq y_{2}$, and (3) $z_{1}+x_{1} y_{1} \leqq z_{2}+x_{2} y_{2}$. Clearly $\leqq$ is a partial order on $L$ and $L$ is a compact, connected portion of $R^{3}$ in its metric topology.

For $\left(x_{1}, y_{1}, z_{1}\right)$ and $\left(x_{2}, y_{2}, z_{2}\right)$ define $a_{1}=x_{1} \cup x_{2}, b_{1}=y_{1} \cup y_{2}$, and $c_{1}=\left[\bigcup_{i=1,2}\left(z_{i}+x_{i} y_{i}-a_{1} b_{1}\right)\right] \cup 0$ where $\cup$ is the lattice operation maximum on the real line under the natural order. Clearly $0 \leqq a_{1} \leqq 1$ and $0 \leqq b_{1} \leqq 1$. Since $z_{i} \leqq x_{i}\left(1-y_{i}\right)=x_{i}-x_{i} y_{i}, \quad z_{i}+x_{i} y_{i} \leqq x_{i} \leqq a_{1}$. Thus $z_{i}+x_{i} y_{i}-a_{1} b_{1} \leqq a_{1}-a_{1} b_{1}=a_{1}\left(1-b_{1}\right)$. Clearly $0 \leqq a_{1}\left(1-b_{1}\right)$, thus $0 \leqq c_{1}$ $=\left[\bigcup_{i=1,2}\left(z_{i}+x_{i} y_{i}-a_{1} b_{1}\right)\right] \cup 0 \leqq a_{1}\left(1-b_{1}\right)$ and $\left(a_{1}, b_{1}, c_{1}\right) \in L$. Clearly $\left(a_{1}, b_{1}, c_{1}\right)$ is an upper bound of $\left(x_{1}, y_{1}, z_{1}\right)$ and $\left(x_{2}, y_{2}, z_{2}\right)$. If $(u, v, w) \in L$ is another upper bound, then $u \geqq x_{i}, v \geqq y_{i}$, and $w+u v \geqq z_{i}+x_{i} y_{i}$ for each $i$. Immediately $u \geqq a_{1}, v \geqq b_{1}, w+u v \geqq 0+a_{1} b_{1}$, and $w+u v$ $\geqq\left(z_{i}+x_{i} y_{i}-a_{1} b_{1}\right)+a_{1} b_{1}$. Thus $u \geqq a_{1}, v \geqq b_{1}$, and $w+u v \geqq c_{1}+a_{1} b_{1}$; and $\left(a_{1}, b_{1}, c_{1}\right)$ is the least upper bound of $\left(x_{1}, y_{1}, z_{1}\right)$ and $\left(x_{2}, y_{2}, z_{2}\right)$.

Similarly for $\left(x_{1}, y_{1}, z_{1}\right)$ and $\left(x_{2}, y_{2}, z_{2}\right)$ define $a_{2}=x_{1} \cap x_{2}, b_{2}=y_{1} \cap y_{2}$ and $c_{2}=\left[\bigcap_{i=1,2}\left(z_{i}+x_{i} y_{i}-a_{2} b_{2}\right)\right] \cap\left[a_{2}\left(1-b_{2}\right)\right]$ where $\cap$ is the lattice operation minimum on the real line under the natural order. Clearly $0 \leqq a_{2} \leqq 1$ and $0 \leqq b_{2} \leqq 1$. Since $z_{i} \geqq 0, x_{i} \geqq a_{2} \geqq 0$, and $y_{i} \geqq b_{2} \geqq 0$; then $z+x_{i} y_{i}-a_{2} b_{2} \geqq 0$. Clearly $a_{2}\left(1-b_{2}\right) \geqq 0$, thus

$$
a_{2}\left(1-b_{2}\right) \geqq c_{2}=\left[\bigcap_{i=i, 2}\left(z_{i}+x_{i} y_{i}-a_{2} b_{2}\right)\right] \cap\left[a_{2}\left(1-b_{2}\right)\right] \geqq 0
$$

and $\left(a_{2}, b_{2}, c_{2}\right) \in L$. Clearly $\left(a_{2}, b_{2}, c_{2}\right)$ is a lower bound of $\left(x_{1}, y_{1}, z_{1}\right)$ and $\left(x_{2}, y_{2}, z_{2}\right)$. If $(u, v, w) \in L$ is another lower bound, then $u \leqq x_{i}$, $v \leqq y_{i}$, and $w+u v \leqq z_{i}+x_{i} y_{i}$ for each $i$. Immediately $u \leqq a_{2}, v \leqq b_{2}$,

Received by the editors February 6, 1956.

1 This work was done under Contract N7-onr-434, Task Order III, Navy Department, Office of Naval Research. 
$w+u v \leqq u(1-v)+u v=u \leqq a_{2}=a_{2}\left(1-b_{2}\right)+a_{2} b_{2}$, and $w+u v \leqq\left(z_{i}+x_{i} y_{i}\right.$ $\left.-a_{2} b_{2}\right)+a_{2} b_{2}$. Thus $u \leqq a_{2}, v \leqq b_{2}$, and $w+u v \leqq c_{2}+a_{2} b_{2}$, and $\left(a_{2}, b_{2}, c_{2}\right)$ is the greatest lower bound of $\left(x_{1}, y_{1}, z_{1}\right)$ and $\left(x_{2}, y_{2}, z_{2}\right)$.

Hence, under the partial order $\leqq, L$ is a lattice with $\left(x_{1}, y_{1}, z_{1}\right)$ $\cup\left(x_{2}, y_{2}, z_{2}\right)=\left(a_{1}, b_{1}, c_{1}\right)$ and $\left(x_{1}, y_{1}, z_{1}\right) \cap\left(x_{2}, y_{2}, z_{2}\right)=\left(a_{2}, b_{2}, c_{2}\right)$. It is clear that the functions $\cup$ and $\cap$ from $L \times L$ to $L$ are continuous functions in the metric topology, and that $(L, \leqq)$ is a topological lattice in this topology.

It remains to show that this lattice is not modular. Denote $\alpha=(0,1,0), \beta=(1,0,0), \gamma=(1,0,1), 0=(0,0,0)$, and $I=(1,1,0)$. Then clearly $\beta<\gamma$, and the trivial computations imply that $\alpha \cap \beta$ $=\alpha \cap \gamma=0$ and $\alpha \cup \beta=\alpha \cup \gamma=I$. Thus $0, \alpha, \beta, \gamma, I$ constitute a nonmodular five lattice and $L$ is not modular.

SOUTHERN METHODIST UNIVERSITY AND

TULANE UNIVERSITY 